\title{
Lita Lundquist, Navigating in Foreign Language Texts
}

Frederiksberg, Denmark: Samfunds Litteratur, 2008

\section{Shirley Carter-Thomas}

\section{CpenEdition}

\section{Journals}

Electronic version

URL: http://journals.openedition.org/asp/240

DOI: $10.4000 / a s p .240$

ISBN: 978-2-8218-0408-1

ISSN: 2108-6354

\section{Publisher}

Groupe d'étude et de recherche en anglais de spécialité

\section{Printed version}

Date of publication: 1 March 2009

Number of pages: 111-113

ISSN: 1246-8185

\section{Electronic reference}

Shirley Carter-Thomas, «Lita Lundquist, Navigating in Foreign Language Texts », ASp [Online], 55 | 2009,

Online since 29 December 2009, connection on 02 November 2020. URL : http://

journals.openedition.org/asp/240 ; DOI : https://doi.org/10.4000/asp.240

This text was automatically generated on 2 November 2020.

Tous droits réservés 


\section{Lita Lundquist, Navigating in Foreign Language Texts}

Frederiksberg, Denmark: Samfunds Litteratur, 2008

Shirley Carter-Thomas

\section{REFERENCES}

Lundquist Lita. 2008. Navigating in Foreign Language Texts. Frederiksberg, Denmark: Samfunds Litteratur. 148 p. ISBN 978-8-75931-417-3. 
1 Concepts and theories in text and cognitive linguistics can sometimes appear rather removed from the practical concerns of language learners. In this informative, yet highly accessible book, Lita Lundquist, Professor of Languages for Specific Purposes at the Copenhagen Business School, shows how they can be put to immediate use. One of the main ideas underpinning Navigating in Foreign Language Texts is that increased awareness of the often subconscious cognitive and linguistic strategies used in the reading and decoding of complex academic texts in readers' own native languages can facilitate the processing of similar texts in a foreign language. Lundquist identifies a number of top-down and bottom-up strategies and demonstrates how they can be used to help process foreign language texts. Four languages are dealt with: English, French, German and Spanish. Although the academic texts examined are mainly business-oriented the techniques presented could be easily applied to specialised texts in other fields.

2 The book is divided into three main parts and is completed with a list of references and an index. In Part One, two chapters are devoted to the description of the top-down procedures readers can call upon when processing texts. Chapter 1 emphasises the importance of activating various knowledge frames when initially accessing a new text. The first words of a text often trigger a whole domain of knowledge. Readers need to be able to situate their expectations about the incoming text within the appropriate knowledge frames so as to delimit the domain within which the text evolves and predict its development. Chapter 2 shows how to exploit certain contextual clues (such as title, author, text source) in order to gain information about genre, discourse type and text type. In conjunction with his/her particular (world) knowledge frame the reader is then able to activate an "interpretation program" (p. 29) that can subsequently be confirmed or revised according to the linguistic signals on the text surface. Both chapters are amply illustrated with examples from the four languages which help the reader to get a firm grasp of these often slippery concepts.

In Part Two, two chapters illustrate a number of bottom-up processes readers can call upon to decode texts. In Chapter 3 Lundquist shows how to exploit clues contained in the text's syntax through "parsing" (p.48) and chunking the sentences into smaller reading units. By decomposing the structure of a sentence into verbs, players/ participants and settings, readers are able to grasp the basic meaning more quickly. Chapter 4 deals primarily with lexis and proposes a number of techniques for decoding unfamiliar words and for unpacking complex nominal groups and phrases. According to Lundquist, the informative density characteristic of many specialised texts tends to be realised via the same sorts of constructions in the four languages examined and 
knowledge of one's native language can therefore be usefully mobilised when confronted with such features in a foreign language text.

Although Part One is primarily concerned with top-down procedures and Part Two with bottom-up procedures, this division is in fact really only organisational, for as Lundquist clearly demonstrates throughout the book the two approaches continually inform each other. Although for example sentence parsing is primarily a bottom-up process - the decoding of incoming linguistic material - the reader is at the same time using top-down processes to predict what will come next. A verb for instance will normally come with a certain number of participants, and this structure thus provides a blueprint for the interpretation of the whole sentence. Similarly, various initial topdown predictions are developed, confirmed or infirmed by the linguistic material at the reader's disposal.

In Part Three, we leave the realm of sentences for that of the text. Chapter 5 first details some of the linguistic means for expressing text coherence, such as theme progression patterns and logical and rhetorical connections. This is followed by a presentation of strategies readers can use to predict the "paths to coherence" (p. 116) characteristic of a particular genre and type of text. In narrative texts for example, which typically explain the events and actions of a main character, readers can often usefully search for one main continued discourse referent or identify time settings in the form of temporal adverbials. Once again top-down strategies are tracked through bottom-up processes. In Chapter 6 the reader is invited to move from the theory to the practice. It is true that despite the numerous illustrations some of the explanations and dissections of texts in previous chapters can appear at times appear rather abstract. Reading is after all a process and difficult to replicate in retrospect. The author overcomes this by presenting two e-learning programmes which simulate the actual left to right process of reading a text in real time. Both programmes propose a range of exercises for the development of text and comprehension skills. The first programme TeXtRay $^{1}$ enables the user to practice dividing up a text into reading units and identifying syntactic constituents and their relations. The programme NaviLire ${ }^{2}$ focuses specifically on the identification of different coherence paths in a range of textual genres and narrative types. Some of the screenshots are not always very readable but perhaps this will encourage readers to access the relevant websites directly. The colour-coding of the various coherence paths in the actual Navlire programme is a particularly helpful feature. These software tools are moreover free of charge and easily downloadable.

6 All in all I found this a highly accessible, useful book. It contains a wealth of ideas for developing reading and text linguistic skills. Among the themes developed in the book that I particularly appreciated are those related to text linguistics and the notion of intercomprehension. Text linguistics is rarely exploited in language teaching and it is refreshing to see some concrete applications being proposed. Throughout the book Lundquist also emphasises the importance of exploiting features shared by the languages examined, rather than focusing on their differences. This is also a common theme in many of the recent EU projects on intercomprehension ${ }^{3}$ and one that is perhaps insufficiently exploited in many of the language teaching materials on the market. The author claims that the book has been written "first and foremost for students in higher education" (p. 7). However whilst some students of language or linguistics may be motivated enough to read it, it seems unlikely to me that learners 
from other disciplines (such as those of the LANSAD sector in France) will be inclined or able to tackle it without guidance. On the other hand, with some prior input from their teachers, they could certainly benefit from using the software packages by themselves. I therefore feel that another arguably more important category of reader could be language teachers, and particularly those involved in teaching LSP. Many of the specialised texts we propose to our students would lend themselves well to the types of exercises proposed in this book. LSP students often lack the strategies necessary for tackling lengthy texts that are often required reading in their fields, and this book fills a very important gap in this respect.

\section{NOTES}

1. <http://www.isvcbs.dk/textray>.

2. <http://panini.u-paris10.fr/jlm>.

3. The term 'intercomprehension' is used to describe a broader approach to language education which particularly emphasises the use of underlying language proficiency to enable access to other languages.

\section{AUTHORS}

\section{SHIRLEY CARTER-THOMAS}

Institut Télécom, Évry 